\title{
Genotypic differences in reaction of barley root system on Mn and Fe toxicity
}

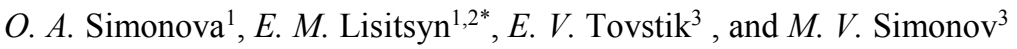 \\ ${ }^{1}$ Federal Agricultural Research Center of the North-East, Kirov, 610007, Russian Federation \\ ${ }^{2}$ Vyatka State Agricultural Academy, Kirov, 610017, Russian Federation \\ ${ }^{3}$ Vyatka State University, Kirov, 610017, Russian Federation
}

\begin{abstract}
The study was performed to determine genotypic differences in spring barley cultivars on resistance to $1.1 \mathrm{mM}$ manganese and $1.2 \mathrm{mM}$ iron at early stage of growth. Resistance level was estimated by morphologic (root length) and physiological (level of antioxidant activity, accumulation coefficient) parameters. Morphologic trait was less sensitive for cultivar differentiation in compare with physiological one. Based on relative root length index all cultivars were classified as resistant having resistance index about $80-94 \%$ for $\mathrm{Mn}$ and $67-76 \%$ for Fe. Reaction to $\mathrm{Mn}$ by change in antioxidant activity was uniform: it was increased from $4 \%$ in cv. Bionic up to $28 \%$ in cv. Farmer. According to reactions to Fe, studied cultivars were divided into three groups: high resistant (cv. Belgorodsky 100 and Farmer; increase in antioxidant activity 2 and $18 \%$ accordingly), weak resistant (cv. Forward, Bionic, and 29-11; changes were insignificant) and sensitive one (cv. 346-09; 8\%-decrease in activity). For manganese accumulation coefficient is higher than for iron. The maximum accumulation coefficient for manganese was characteristic of cv. 29-11 (190), for iron - cv. Bionic (120). The genotypic specificity for root antioxidant activity can be used as a rapid test of resistance to manganese or iron in initial breeding material.
\end{abstract}

\section{Introduction}

Creation of highly productive genotypes of agricultural crops resistant to adverse environmental factors including heavy metal pollution has become a major global problem of plant breeding. Heavy metals in high concentrations contribute to slowing plant development, disrupting physical-biochemical processes, which can lead to reduced yields and even death of plants.

Agricultural soils of the Kirov region of the Russian Federation are most often acidic low-buffer soils, which contributes to increasing solubility of heavy metal compounds and exceeding the maximum permissible concentrations of their mobile forms [1]. Manganese and iron refer to elements whose solubility increases with decrease of soil solution $\mathrm{pH}$ : maximum amounts of manganese are noted at $\mathrm{pH}<5.5$ [2]; iron solubility increases by a thousand times at decrease of $\mathrm{pH}$ from 5 to 4 [3]. As a result, these elements become

*Corresponding author: edaphic@mail.ru 
readily available to plants; their biological absorption coefficient is higher than one and plants can accumulate them in high quantities. Excessive concentrations of manganese and iron contribute to both slowing plant growth and changing biochemical processes such as the generation of oxidative stress; disorder of photosynthesis, respiration, biosynthesis of chlorophyll; disturbance of suction and movement of mineral elements; all these disorders eventually lead to plant death $[4,5]$.

Spring barley (Hordeum vulgare L.) takes a leading position in the structure of grain crops of the Kirov region, so the plant breeders in Federal Agricultural Research Center of the North-East actively working on the creation of cultivars adapted to the conditions of acidic soils. Breeders use integral physiological and morphometric parameters of ecological resistance of plants grown in laboratory and greenhouse conditions, including level of accumulation of heavy metals in plant organs, to assess selection suitability of initial collecting material. One of the most important characteristics of stress resistance of different nature is antioxidant activity of plant tissues.

This research was conducted to determine genotypic differences of spring barley cultivars by response of plantlets' root systems to presence of increased concentrations of manganese and iron.

\section{Materials and methods}

The objects of the study were barley plants of the following cultivars: Belgorodsky 100, 346-09, 29-11, Farmer, Forward, and Bionic from the working collection of the laboratory of barley breeding and primary seed growing of FARC North-East.

Plants were grown for 7 days in a thermostat at $21 \ldots 230 \mathrm{C}$ in filter paper towels $(16 \mathrm{~cm}$ $\times 100 \mathrm{~cm}, 1 \mathrm{~cm}$ from the top) according to the procedure [6]. Towels were placed in glass beakers with control or experiment solution. Each variant had a 3-fold replication of 33 plants. Experiment design: 1 - distilled water (Control); 2 - distilled water with addition of $1.1 \mathrm{mM}$ manganese as $\mathrm{MnSO} 4 \times \mathrm{H} 2 \mathrm{O}$ (corresponds to concentration of $60 \mathrm{mg} / \mathrm{kg}$ soil); 3 distilled water with addition of $1.2 \mathrm{mM}$ iron as FeSO4. $7 \mathrm{H} 2 \mathrm{O}$ (corresponding to concentration of $67 \mathrm{mg} / \mathrm{kg}$ soil).

The potential resistance of barley plantlets to manganese and iron was assessed by the length of the largest root, relative root length (RRL) and antioxidant activity of the roots. RRL was calculated as the ratio of average root length in experimental and control variants multiplied by $100 \%$. Each experiment had triple repetition.

The antioxidant activity of the root tissues of barley plantlets was assessed by their ability to inhibit the auto-oxidation of adrenaline and thereby prevent the formation of active oxygen species [7]. The antioxidant activity of the root tissues was determined in extract of 0.90-1.00 $\mathrm{g}$ fresh roots in $10 \mathrm{ml}$ bicarbonate buffer ( $\mathrm{pH} \mathrm{10.3 \ldots 10.6).} \mathrm{Antioxidant}$ activity (AOA) was calculated by the formula:

$$
\mathrm{AOA}=(\mathrm{OD} 1-\mathrm{OD} 2) *(\mathrm{OD} 1)-1 * 100 \%,
$$

wherein OD1 is an optical density of $3 \mathrm{ml}$ of bicarbonate buffer with the addition of 0.1 $\mathrm{ml}$ of $0.1 \%$ adrenaline hydrochloride solution, OD2 is optical density of $2 \mathrm{ml}$ of buffer with addition of $1 \mathrm{ml}$ of filtrate and $0.1 \mathrm{ml}$ of $0.1 \%$ solution of adrenaline hydrochloride.

The optical density was measured after 2 hours storage with an UVmini-1240 spectrophotometer (Shimadzu Corporation, Japan) at $347 \mathrm{~nm}$.

Also in the roots of the plantlets, the content of manganese and iron was determined with the atomic absorption spectrophotometer AA-6800 (Shimadzu, Japan). The accumulation coefficient (AC), defined as the plant/medium concentration quotient [8] was calculated. $\mathrm{AC}=\mathrm{Croot} / \mathrm{Cmedium}$ where $\mathrm{Croot}=$ concentration of metal in barley plantlets root part (mg kg-1) and Cmedium = concentration in growth solution (mg kg-1). 
Experimental data processing was carried out by the methods of variation statistics using the Microsoft Excel software package. The tables show the average values of the parameters and their standard deviations. In work the values are discussed significantly different from control variant at $\mathrm{p} \leq 0.05$

\section{Results}

The evaluation of the linear growth of plants on the root length allowed to establish the toxic effect of manganese ions on all the cultivars studied (table 1). Data of table 1 show a natural decrease in root length in experimental groups of barley plantlets compared to control. The largest decrease in root length in the experimental groups compared to the control was observed in cv. Belgorodsky 100. By RRL value, according to Navacode et al. scale [9], all studied cultivars can be classified as resistant (RRL is above 60\%).

Table 1. Influence of Mn on root system of barley plantlets.

\begin{tabular}{|c|c|c|c|c|c|}
\hline \multirow[b]{2}{*}{ Variant } & \multicolumn{2}{|c|}{ Root length } & \multicolumn{2}{|c|}{$\mathrm{AOA}$} & \multirow{2}{*}{$\begin{array}{l}\text { Mn content in } \\
\text { root } \\
\mathrm{mg} \mathrm{kg}^{-1}\end{array}$} \\
\hline & $\mathrm{cm}$ & RRL & $\%$ & $\begin{array}{l}\% \text { to } \\
\text { control }\end{array}$ & \\
\hline \multicolumn{6}{|c|}{ cv. Belgorodsky 100} \\
\hline Control & $15.2 \pm 0.4$ & & $91.16 \pm 0.94$ & & $133.53 \pm 21.14$ \\
\hline $1.1 \mathrm{mM} \mathrm{Mn}$ & \multicolumn{5}{|c|}{ cv. 346-09 } \\
\hline Control & $16.7 \pm 0.2$ & & $87.72 \pm 2.53$ & & $102.18 \pm 14.77$ \\
\hline $1.1 \mathrm{mM} \mathrm{Mn}$ & $15.7 \pm 0.3 *$ & 94.01 & $\begin{array}{l}98.57 \pm 0.13 * \\
\text { orward }\end{array}$ & 112.37 & $5331.89 \pm 120.25$ \\
\hline Control & $16.6 \pm 0.5$ & & $76.89 \pm 7.75$ & & $366.44 \pm 2.42$ \\
\hline $1.1 \mathrm{mM} \mathrm{Mn}$ & $15.4 \pm 0.3 *$ & 92.77 & $\begin{array}{l}84.14 \pm 3.33 * \\
\text { armer }\end{array}$ & 109.42 & $3787.44 \pm 189.45$ \\
\hline Control & $16.5 \pm 0.2$ & & $68.26 \pm 0.36$ & & $67.01 \pm 2.16$ \\
\hline $1.1 \mathrm{mM} \mathrm{Mn}$ & $14.5 \pm 0.7 *$ & 87.88 & $\begin{array}{l}87.55 \pm 2.03 * \\
29-11\end{array}$ & 128.26 & $8023.23 \pm 19.60$ \\
\hline Control & $15.1 \pm 0.4$ & & $90.08 \pm 0.26$ & & $77.85 \pm 4.61$ \\
\hline $1.1 \mathrm{mM} \mathrm{Mn}$ & $13.4 \pm 0.1 *$ & \multicolumn{3}{|c|}{ Bionic } & $11413.46 \pm 220.00$ \\
\hline Control & $15.6 \pm 0.6$ & & $91.13 \pm 1.16$ & & $158.71 \pm 2.14$ \\
\hline $1.1 \mathrm{mM} \mathrm{Mn}$ & $14.2 \pm 0.3^{*}$ & 91.03 & $94.99 \pm 0.19^{*}$ & 104.23 & $9465.33 \pm 486.49$ \\
\hline
\end{tabular}

* - Values are significantly different from control at $\mathrm{p} \leq 0.05$

The lowest values of antioxidant activity in the control variant were recorded in two cultivars: Forward $(76.89 \%)$ and Farmer $(68.26 \%)$, which allows them to be considered as potentially sensitive to oxidative stress. The degree of potential resistance to oxidative stress of the remaining cultivars is approximately equal. The change in antioxidant activity under influence of manganese ions was statistically significant for all cultivars studied, increasing from 4.2 (cv. Bionic) to $28.3 \%$ (cv. Farmer). The cv. Farmer according to this parameter can be considered the most Mn-stress resistant; the least resistant one were cultivars 29-11 and Bionic, which increased the level of antioxidant activity by only $4-5 \%$.

Statistically significant differences between cultivars are noted for manganese content in root tissues. Under control conditions, the maximum content of the element is recorded in cv. Forward (366.44 mg kg-1) and the minimum content in cv. Farmer (67.01 mg kg-1). When manganese was added to the growing medium, the highest level of its entry into the barley root system was found in cultivars 29-11 and Farmer, exceeding the control values by 147 and 120 times, respectively. Within studied cultivars cv. Forward absorbed 
manganese from the growing medium in the smallest degree, exceeding the content of the element in the roots relative to the control by only 10 times. Roots of plantlets of $\mathrm{cv}$. Belgorodsky 100, 346-09 and Bionic contained 40-60 times more manganese than under control conditions.

The effect of increased iron ion content in the growth medium was also evident on the plant root linear growth parameter (table 2). At the same time toxic effect of iron ions on all studied cultivars was more significant than when exposed to manganese ions: on average RRL index was 70.56 and 89.12 respectively. Although the highest RRL was $76.16 \%$ (in cv. 29-11), all cultivars could nevertheless be classified as resistant one according to Navacode et al. scale [9] (RRL is above 60\%).

Table 2. Influence of $\mathrm{Fe}$ on root system of barley plantlets.

\begin{tabular}{|c|c|c|c|c|c|}
\hline \multirow{2}{*}{ Variant } & \multicolumn{2}{|c|}{ Root length } & \multicolumn{2}{|c|}{$\mathrm{AOA}$} & \multirow{2}{*}{$\begin{array}{l}\mathrm{Fe} \text { content in } \\
\text { root } \mathrm{mg} \mathrm{kg}^{-1}\end{array}$} \\
\hline & $\mathrm{cm}$ & RRL & $\%$ & $\%$ to control & \\
\hline \multicolumn{6}{|c|}{ cv. Belgorodsky 100} \\
\hline Control & $15.2 \pm 0.4$ & & $91.16 \pm 0.94$ & & $86.78 \pm 5.76$ \\
\hline $1.2 \mathrm{mM} \mathrm{Fe}$ & $11.3 \pm 0.2 *$ & 74.34 & $93.27 \pm 0.36^{*}$ & 102.31 & $3029.42 \pm 44.68$ \\
\hline \multicolumn{6}{|c|}{ cv. 346-09 } \\
\hline Control & $16.7 \pm 0.2$ & & $87.72 \pm 2.53$ & & $130.61 \pm 22.83$ \\
\hline $1.2 \mathrm{mM} \mathrm{Fe}$ & $11.5 \pm 0.5^{*}$ & 68.86 & $81.12 \pm 1.26^{*}$ & 92.48 & $3249.39 \pm 63.30$ \\
\hline \multicolumn{6}{|c|}{ cv. Forward } \\
\hline Control & $16.6 \pm 0.5$ & & $76.89 \pm 7.75$ & & $206.99 \pm 18.81$ \\
\hline $1.2 \mathrm{mM} \mathrm{Fe}$ & $11.0 \pm 0.5^{*}$ & 66.26 & $86.74 \pm 4.23$ & 112.81 & $5956.29 \pm 56.37$ \\
\hline \multicolumn{6}{|c|}{ v. Farmer } \\
\hline Control & $16.5 \pm 0.2$ & & $68.26 \pm 0.36$ & & $92.72 \pm 15.72$ \\
\hline $1.2 \mathrm{mM} \mathrm{Fe}$ & $11.2 \pm 0.7 *$ & 67.88 & $80.96 \pm 0.73 *$ & 118.61 & $1537.95 \pm 53.30$ \\
\hline \multicolumn{6}{|c|}{ cv. $29-11$} \\
\hline Control & $15.1 \pm 0.4$ & & $90.08 \pm 0.26$ & & $165.48 \pm 6.60$ \\
\hline $1.2 \mathrm{mM} \mathrm{Fe}$ & $11.5 \pm 0.4^{*}$ & 76.16 & $87.60 \pm 4.24$ & 97.24 & - \\
\hline \multicolumn{6}{|c|}{ cv. Bionic } \\
\hline Control & $15.6 \pm 0.6$ & & $91.13 \pm 1.16$ & & $128.77 \pm 5.26$ \\
\hline $1.2 \mathrm{mM} \mathrm{Fe}$ & $10.9 \pm 0.4 *$ & 69.87 & $91.15 \pm 1.10$ & 100.02 & $7812.13 \pm 17.61$ \\
\hline
\end{tabular}

* - Values are significantly different from control at $\mathrm{p} \leq 0.05$

Unlike manganese exposure, in this case significant differences from control were found in only three cultivars: Belgorodsky 100, 346-09, and Farmer. At the same time in cv. 34609 there was a decrease of AOA by $7.5 \%$, in two others - an increase by $2-18 \%$. The trend towards higher AOA levels was noted for the cv. Forward, but this difference from control was not statistically significant. Thus, unlike the uniform reaction to manganese ions (expressed as increase in AOA), the studied cultivars of spring barley showed different response to iron ions: three cultivars did not change their antioxidant activity in any way, two cultivars increased it, and one cultivar reduced it.

The maximum content of iron in the roots in the control variant was found in the $\mathrm{cv}$. Forward, and the minimum - in the cv. Belgorodsky 100. Under the conditions of iron ions influence, the largest amount of iron was accumulated by the cv. Bionic, having exceeded by this parameter the control variant by 60 times. Plants of cv. Farmer accumulated the smallest relative amount of element (16.5 times more than in control). In the remaining cultivars, the excess of the element content over the control variants was 25-35 times. However, in general, the iron ion input to the barley plantlet roots in the experimental variants was lower than the manganese input. The exception was the cv. Bionic, for which the excess of accumulation of both elements over control values was equally high. 
Based on data on the content of the studied elements in the growth medium and the roots of barley plantlets, genotypic differences in the accumulation rates of both metals were analyzed, i.e. the ability of plants to absorb these elements from the growth medium (Figure).

For both elements, the accumulation coefficients (CA) were quite high. However, the CA of manganese is significantly higher than iron, especially in the cv. Farmer (133.72 and 23.66, respectively). The exception was the cv. Forward, which had a higher CA value for iron compared to manganese. The maximum CA for manganese was characteristic of $\mathrm{cv}$. 29-11, for iron was characteristic of cv. Bionic.

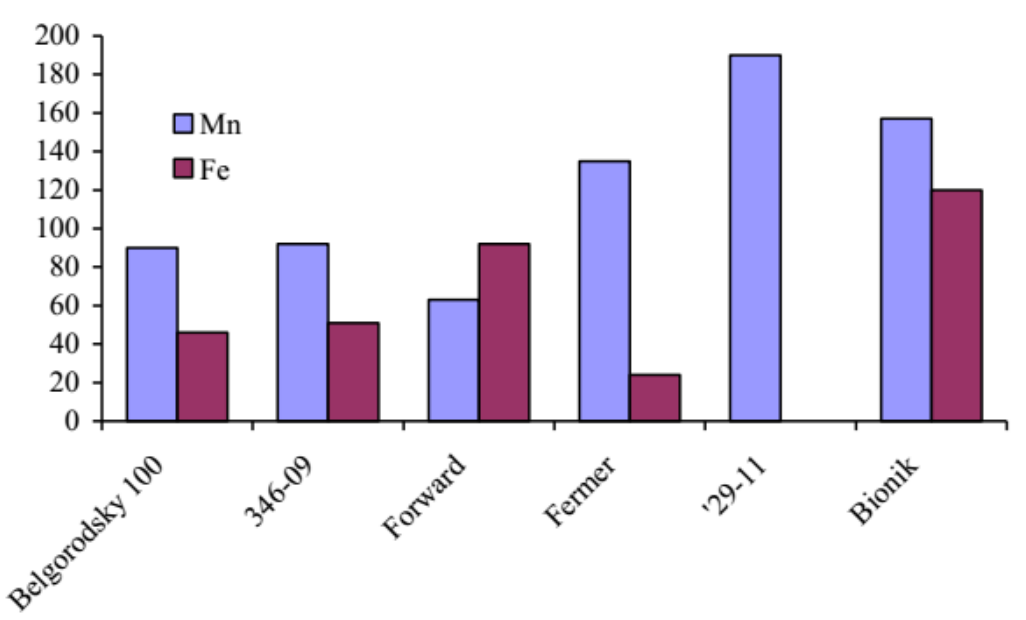

Figure 1. Accumulation coefficient for $\mathrm{Mn}$ and $\mathrm{Fe}$ in roots of barley plantlets.

\section{Discussion}

According to [3], the concentration of manganese equal to $4.2 \mathrm{mg} \mathrm{kg}-1$ and iron equal to $2.6 \mathrm{mg} \mathrm{kg}-1$ is optimal for barley plants cultivated under the conditions of sod-podzolic soils. Therefore, the selected concentrations of the elements are stressful for barley plants and have a negative effect on their development, which has been shown in our work on the example of linear dimensions of barley plantlet root systems. At present, the investigation of development of root systems attracts less attention of researchers and plant breeders, while many indicators of the development of aboveground parts of plants used in breeding for stress resistance have been developed [10]. However, under the conditions of various abiotic stress factors, including toxic concentrations of metals, root systems play a significant role in the successful development of the plant [11]. The resistance parameters of root systems can serve as express information on the response of plants to such stressors. For example, morphological parameters of root development are successfully used in breeding of cereal crops for aluminum resistance in conditions of acidic soils of European NonChernozem Zone [12]. According to other researchers, the degree of toxicity symptoms of manganese ions was inversely correlated with the relative dry mass of the wheat root $(\mathrm{r}=$ -0.83 ), and the root system of wheat has high sensitivity to toxic effects of iron [13]. Thus, this parameter can be used as a tool to investigate the influence of heavy metals on plant development. In our work, the cv. Belgorodsky 100 was less resistant to manganese by root growth parameters than the new cultivars of spring barley bred in FARC NorthEast (Kirov, 
Russian Federation). On the other hand, this cv. Belgorodsky 100 proved to be more resistant to iron than the rest of the studied cultivars.

The metals studied also had an effect on the antioxidant activity of the roots. Antioxidant activity is determined as the ability of bioactive compounds to prevent, delay, and protect against action of free oxygen radicals in plant or animal organisms [14]. Although genetic processes guide the production of antioxidant compounds in plants, it is also strongly influenced by external factors. Therefore, such factors as heavy metals cause changes in the growth of plants, as well as the quantity of their antioxidant substances [15]. For example, [16] shown significant increase in antioxidant activity when plant were exposed to toxic levels of Mn. Observed changes could be the result of the oxidative stress induced by high concentrations of $\mathrm{Mn}$.

Unlike the effect on morphological parameters (absolute and relative root length), in our study manganese had a greater effect on antioxidant activity than iron. On the one hand, there is much in common between these elements in their physiological role for plant development [3]. However, the effect of $\mathrm{Mn}$ on AOA-related processes in higher plants is assumed to be different from that of $\mathrm{Fe}$ [17]. Our study also demonstrated significant genotypic differences in the response of antioxidant systems of barley plantlets to the metals used. In the case of manganese, an increase in antioxidant activity was observed in all cultivars studied; and in iron influence, a significant change was observed only in three cultivars, of which two cultivars had an increase in this parameter. Since it is known that antioxidant performance such as antioxidant activity (AOA) and antioxidant enzymes such as superoxide dismutase (SOD) were activated in presence of excess Mn [18], probably in different barley genotypes disorders are associated with different biochemical reactions (increase in synthesis of enzymes, secondary metabolites, lipid peroxidation of membranes). In contrast, other studies shown that the antioxidant system decreases its activity due to the effects of $\mathrm{Mn}$ [19] and these contrasting antioxidant responses when facing excess $\mathrm{Mn}$ are directly influenced by $\mathrm{Mn}$ resistance and sensitivity mechanisms in plants [18]. Millaleo et al. [18] on example of four barley cultivars showed that Mnresistant varieties increased AOA and sensitive cultivars decreased AOA. According to these observations, all barley varieties studied by us are considered as potentially resistant to manganese ions, but differ in resistance to iron ions: cv. Belgorodsky 100 and Farmer are highly resistant (significantly increase the level of AOA compared to control), cv. 346-09 is sensitive one (reduces the level of AOA), and the rest cultivars are weak resistant (not significant changes in AOA).

We also investigated the content and input of heavy metals into the root system of barley plantlets. The presence of a certain amount of metals in the control variants can be explained by the fact that all cultivars have been reproduced under acidic sod-podzolic soil conditions, in which the manganese content can reach $541 \mathrm{mg} \mathrm{kg}-1$ [20], and the only manganese source in the root tissues under the control conditions is plant seeds. According to other researchers, manganese content in grain of spring cereals can reach values of 40 $100 \mathrm{mg} \mathrm{kg-1}$ [21-23] depending on soil type. In our studies, the content and input of metals into the root system of plants because of their addition to the growing medium was different in different cultivars. The results are consistent with the data of other scientists that the input and accumulation of elements in plants depends not only on the species, but also on the cultivar (genotype) within the species [13]. These differences are related to plant resistance mechanisms. It is known that there are two different strategies for the survival of organisms under stress: "avoidance" when the plant in one way or another restricts the entry of toxic ions into cells, or "tolerance" [4]. An example of avoidance in the case of Mn toxicity is the binding of toxic ions by organic acids synthesized by roots. For example, Mora et al. [24] reported that root exudates of oxalate and citrate could reduce the availability of $\mathrm{Mn}$ in the ryegrass rhizosphere, increasing its Mn-resistance. 
In our research, both elements: manganese at concentration of $1.1 \mathrm{mM}$ and iron at concentration of $1.2 \mathrm{mM}$ had an effect on both root length and their antioxidant activity. At the same time, despite the fact that higher iron concentrations had a negative impact on the root system of barley plantlets, their death was not observed. On the one hand, as mentioned above, plants have mechanisms for resistance to adverse factors, including excessive concentrations of heavy metals. On the other hand, by increasing the content of elements in the growing medium, their entry into plants is increased, but significant genotypic differences in the metal accumulation coefficient are observed.

\section{Conclusions}

The effect of manganese and iron ions on the growth of spring barley plantlets is significantly different. The data from the work do not make it clear which of the elements is more toxic. On the one hand, when exposed to iron, the root length is reduced to a greater extent, but the AOA change and entry of the element into plants is lower than when manganese ions are added. At the same time, according to the value of RRL all studied cultivars belong to the resistant group in the case of influence of both iron and manganese. However, unlike the uniform reaction to manganese ions (increase in AOA), studied cultivars showed different reactions to the iron ions: three cultivars (Forward, Bionic, and 29-11) did not change antioxidant activity in any way, two cultivars (Belgorodsky 100 and Farmer) increased it, and one cultivar (346-09) reduced it.

However, according to the indicators of element accumulation and change in the level of antioxidant activity of root tissues, varieties can be surely differentiated by resistance to manganese and iron ions. According to the parameter of change of antioxidant activity, the most resistant to manganese action was cv. Farmer (increase in AOA by 28.3\%), the least resistant were cultivars 29-11 and Bionic, which increased the level of antioxidant activity by only $4-5 \%$. Under the influence of iron ions, differences from control were revealed in only three cultivars: Belgorodsky 100, 346-09 and Farmer. At the same time in cv. 346-09 there was a decrease of AOA by $7.5 \%$, in two others - an increase by $2-18 \%$.

The genotypic specificity for antioxidant activity of roots shown in the work can be used as a rapid assessment of the initial material in breeding for resistance to acidic soils with high amount of manganese or iron.

\section{References}

1. Shikhova L N 2017 Heavy Metals and Other Pollutants in the Environment. Biological Aspects (Ed. G E Zaikov, L I Weisfeld, E M Lisitsyn, S A Bekuzarova. New York: Apple Academic Press) pp 3-30.

2. Kogelmann W and Sharpe W 2006 J. Environ. Qual. 35 433-441.

3. Nebolsin A N and Nebolsina Z P 2005 Theoretical bases of soil liming (Saint Petersburg: Leningrad Agricultural Research Institute Press) p 252 (In Russian)

4. Millaleo R, Reyes-Díaz M, Ivanov A G, Mora M L and Alberdi M 2010 J. Soil Sci. Plant Nutr. 10(4) 476-94

5. Shevyakova N I, Eshinimaeva B C, Paramonova N V and Kuznetsov V V 2009 Russian Plant Physiology 56(4) 518-529 (In Russian)

6. Lisitsyn E M 2000 Intravarietal J. Plant Nutrit. 23(6) 793-804

7. Sirota T V 2000 Method of assessing antioxidant activity of superoxide dismutase and chemical compounds Patent RF, no. 144674 (in Russian). 
8. Gworek B, Klimczak K and Kijeńska M 2014 Phragmites communis, Polygonum persicaria and Bidens tripartita. PLoS ONE 9(10): e109548.

9. Navacode S, Weidner A, Varshney R K, Lohwasser U, Scholz U, Roder M S and Borner A 2010 Agric. Conspec. Sci. 75(4) 191-196

10. Den Herder G, Van Isterdael G, Beeckman T and De Smet I 2010 Trends Plant Sci. 15 600-607

11. Raza A, Imtiaz M and Mohammad W 2015 Sustainable Agriculture Reviews 18 295-315

12. Lisitsyn E M 2018 Vestnik of the Mari State University. Chapter "Agriculture. Economics" 4(3) 35-42 (In Russian)

13. Khabaz-Saberi H, Rengel Z, Wilson R and Setter T L 2010 J. Plant Nutr. Soil Sci. 173 103-112

14. Chaves N, Santiago A and Alías J C 2020 Antioxidants 976

15. Zargoosh Z., Ghavam M., Bacchetta G and Tavili A 2019 Scrophularia striata Boiss. Sci Rep 916021

16. Muzolf-Panek M, Kleiber T and Kaczmarek A 2017 Food Additives \& Contaminants: Part A, 34(3)379-389

17. Denre M, Bhattacharya A, Pal S, Chakravarty A, Chattopadhyay A and Mazumdar D 2014 Int. J. Plant Physiol. Biochem. 6 19-27

18. Millaleo R, Rao M, Ulloa-Inostroza E, Duran P and Mora M 2018 J. Soil Sci. Plant Nutrit. 18(4) 1206-1223

19. Li P, Song A, Li Z, Fan F and Liang Y 2012 Plant Soil. 354 407-419.

20. Simonova O A, Lisitsyn E M and Tovstik E V 2019 Estestvennye_i_tehnicheskie_nauki 10 127-131 (In Russian)

21. Newman R K and Newman C W 2008 Barley for Food and Health: Science, Technology, and Products (John Wiley \& Sons, Inc.) p 245

22. Redshaw E S, Martin P J and Laverty D H 1978 Can. J. Anim. Sci. 58 553-558

23. Ullah A, Farooq M, Rehman A, Arshad M, Shoukat H, Nadeem A, Nawaz A, Wakeel A and Nadeem F 2018 Experimental Agriculture, 54(5), 744-754

24. Mora M, Rosas A, Ribera A and Rengel R 2009 Plant Soil 320 79-89 